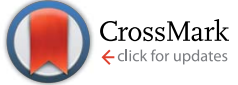

Cite this: RSC Adv., 2016, 6, 74500

\title{
Gadolinium-doped magnetite nanoparticles from a single-source precursor $\dagger$
}

\author{
F. J. Douglas, ${ }^{a}$ D. A. MacLaren, ${ }^{\text {bb }}$ N. Maclean, ${ }^{a}$ I. Andreu, ${ }^{c}$ F. J. Kettles, ${ }^{a}$ F. Tuna, ${ }^{d}$ \\ C. C. Berry, ${ }^{e}$ M. Castro ${ }^{C}$ and M. Murrie ${ }^{* a}$
}

Received 15th July 2016

Accepted 19th July 2016

DOI: $10.1039 / \mathrm{c} 6 \mathrm{ra} 18095 \mathrm{~g}$

www.rsc.org/advances

\begin{abstract}
An iron and gadolinium-containing bimetallic polynuclear complex was used as a single source precursor in the synthesis of gadolinium-doped magnetite nanoparticles $\left(\mathrm{Gd}: \mathrm{Fe}_{3} \mathrm{O}_{4}\right)$. The synthesis produces well defined octahedral particles ( $12.6 \pm 2.6 \mathrm{~nm}$ diameter) with a gadolinium content in the region of $2 \mathrm{~mol} \%$. The nanoparticles showed a value of the specific absorption rate of $3.7 \pm 0.6 \mathrm{~W} \mathrm{~g}_{\mathrm{Fe}}{ }^{-1}$ under lowamplitude radiofrequency magnetic field excitation, and moderate biocompatibility, suggesting that these particles are viable candidates for magnetic hyperthermia applications.
\end{abstract}

\section{Introduction}

The last decade has seen a surge in interest in the synthesis and characterisation of nanoparticles (NPs), driven by their unique properties and their potential uses across a range of applications. Magnetic nanoparticles (MNPs) are amongst the most intensively studied, and in medical applications have both therapeutic and diagnostic prospects, as agents for magnetic hyperthermia $(\mathrm{MH}){ }^{1}$ drug delivery and magnetic resonance imaging (MRI) contrast. ${ }^{2,3}$ However, creating MNPs that are 'tuned' for specific purposes is far from trivial and careful refinement of synthetic procedures is essential to gain precise control over the particle morphology, composition and magnetic properties including the saturation magnetisation, remnant magnetisation and coercivity. ${ }^{4-7}$ Much of the literature focuses on metal oxides, particularly magnetite, because of its ease of production, stability and biocompatibility - some iron oxide nanospecies are already approved by the FDA and the European Commission for clinical applications ${ }^{8,9}$ and have been used in clinical trials. ${ }^{\mathbf{1 0 , 1 1}}$

An interesting prospect is to further enhance the properties of MNPs through doping, such as the use of low levels of $\mathrm{Zn}^{2+}$ doping in ferrite particles to enhance their MRI and MH effect. ${ }^{12}$ Here, we focus on the composite material gadolinium-doped

${ }^{a}$ WestCHEM, School of Chemistry, University of Glasgow, Glasgow G12 8QQ, UK E-mail: Mark.Murrie@glasgow.ac.uk; Tel: +441413304486

${ }^{b}$ SUPA, School of Physics and Astronomy, The University of Glasgow, Glasgow 612 8QQ, UK. E-mail: dmaclaren@physics.org; Tel: +44 1413305886

'Instituto de Ciencia de Materiales de Aragón (ICMA), CSIC - Universidad de Zaragoza, Campus Río Ebro, María de Luna, 3, 50018 Zaragoza, Spain

${ }^{d}$ National EPR Centre, University of Manchester, Oxford Road, Manchester, M13 9PL, $U K$

${ }^{e}$ Centre for Cell Engineering, CMVLS, University of Glasgow, Glasgow G12 8QQ, UK

$\uparrow$ Electronic supplementary information (ESI) available: Experimental details, additional microscopy images. See DOI: 10.1039/c6ra18095g magnetite ( $\left.\mathrm{Gd}: \mathrm{Fe}_{3} \mathrm{O}_{4}\right)$. Gd doping or labelling has been shown to improve the MRI contrast of iron oxide NPs via $T_{1}$ enhancement, ${ }^{13-17}$ whereas the $\mathrm{MH}$ properties of gadolinium-doped magnetite have received much less attention.,18 Whilst doping ions into MNPs is simple in principle, establishing reproducible synthetic procedures can be difficult. For example, coprecipitation or simultaneous decomposition protocols require the metal precursors to react/decompose with similar kinetics if both metals are to be incorporated within a single product. ${ }^{19}$ Differences in reactivity could lead to inhomogeneous products or complete segregation into two discrete nanoparticle populations, a problem that motivates the present report. Our own initial attempts to control the simultaneous decomposition of separate iron- and gadolinium-containing precursors were unreliable, often resulting in distinct nucleation of two NP species. ${ }^{20}$ For this reason we elected to synthesise and use a novel single-source precursor, a bimetallic iron/gadolinium complex. This is advantageous in nanoparticle synthesis because decomposition of the precursor is guaranteed to release iron and gadolinium ions into the reaction mixture simultaneously, which should reduce separate nucleation and low dopant ion uptake. A further advantage of this protocol is that polynuclear precursors can also provide an extra degree of freedom with which to optimise a reaction. ${ }^{5}$

\section{Experimental}

\section{Materials and methods}

$\mathrm{GdCl}_{3} \cdot 2 \mathrm{H}_{2} \mathrm{O}(99 \%), \mathrm{FeCl}_{2} \cdot 4 \mathrm{H}_{2} \mathrm{O}(99 \%)$, sodium benzoate (99\%), benzyl ether (98\%), oleic acid (90\%), oleyl amine (70\%), acetonitrile $(\mathrm{MeCN})$ and diethyl ether $\left(\mathrm{Et}_{2} \mathrm{O}\right)$ were purchased from Sigma Aldrich and used as received without further purification.

\section{Synthesis of the $\mathrm{Fe} / \mathrm{Gd}$ precursor}

The synthesis was adapted from that used to prepare $\left[\mathrm{Fe}_{2}\right.$ $\left.\mathrm{CuO}\left(\mathrm{O}_{2} \mathrm{CPh}\right)_{6}\left(\mathrm{H}_{2} \mathrm{O}\right)_{3}\right] .{ }^{21}$ A solution of sodium benzoate $(1.88 \mathrm{~g}$, 
$13 \mathrm{mmol})$ in $\mathrm{H}_{2} \mathrm{O}(100 \mathrm{~mL})$ was added to a stirred solution of $\mathrm{FeCl}_{2} \cdot 4 \mathrm{H}_{2} \mathrm{O}(0.5 \mathrm{~g}, 2.5 \mathrm{mmol})$ and $\mathrm{GdCl}_{3} \cdot 2 \mathrm{H}_{2} \mathrm{O}(0.46 \mathrm{~g}, 1.25$ $\mathrm{mmol})$ in $\mathrm{H}_{2} \mathrm{O}(50 \mathrm{~mL})$. MeCN $(25 \mathrm{~mL})$ was then added to this solution. The reaction mixture was stirred overnight at ambient temperature to give a light brown precipitate. This precipitate was collected by filtration and washed with $\mathrm{Et}_{2} \mathrm{O}$ (see ESI $\dagger$ ).

\section{Synthesis of Gd:Fe $\mathrm{O}_{3}$ NPs}

$0.2 \mathrm{~g}$ of the $\mathrm{Fe} / \mathrm{Gd}$ air-dried precursor was added to a reaction mixture consisting of oleylamine : oleic acid : benzyl ether in the ratio $4.5: 3: 2.5 \mathrm{~mL}$. The mixture was then heated to $110{ }^{\circ} \mathrm{C}$ under a nitrogen flow for 30 minutes. The nitrogen flow was reduced and the mixture was slowly heated to $310{ }^{\circ} \mathrm{C}$ for 30 minutes. The mixture was then cooled to room temperature and the particles were precipitated with excess ethanol and collected via centrifugation as a black/brown residue and redispersed in hexane.

\section{Transmission electron microscopy and elemental analysis}

Samples were prepared for Transmission Electron Microscopy (TEM) characterisation by dispersing a small amount of dilute hexane particle dispersion directly onto a holey-carbon coated copper TEM grid. TEM and scanning TEM (STEM) were performed on a Tecnai TF20 operated at $200 \mathrm{kV}$. The microscope was fitted with an EDAX Energy dispersive X-ray spectroscopy (EDX) system and a Gatan Enfina Spectrometer for Electron Energy Loss Spectroscopy (EELS) measurements. TEM data were obtained and processed using either Digital Micrograph or IMAGEJ 1.41 software.

\section{Magnetic measurements}

Magnetic measurements were performed on the oleateprotected NPs using a Quantum Design MPMS-XL7 SQUID magnetometer. Samples were fixed in eicosane in gelatine capsules prior to measurement. Data have been corrected for the contributions of the sample holder and eicosane matrix.

\section{Aqueous phase transfer}

To test the potential of the Gd: $\mathrm{Fe}_{3} \mathrm{O}_{4}$ NPs for biological applications, the hydrophobic oleate surfactant of the as-synthesized particles was replaced with a water-dispersible PEG derivative ligand (PEG600-DPA) as described elsewhere.,

\section{Cell culture}

Human dermal fibroblasts cell line h-TERT BJ1 were cultured and expanded in DMEM/10\% FBS (100 $\mathrm{U} \mathrm{mL}^{-1}$ penicillin, 1000 $\mu \mathrm{g} \mathrm{mL}{ }^{-1}$ streptomycin) and maintained at $37^{\circ} \mathrm{C}$ in $5 \% \mathrm{CO}_{2}$ until $\sim 90 \%$ confluent. Cells were seeded at a density of $1 \times 104$ cells per ml. Prior to incubation, particles suspensions were filter sterilised $(0.2 \mu$ filter $)$ and diluted in fresh media to the required concentration.

\section{MTT assay}

To assess the toxicity of the NPs, the cell metabolic activity was determined via an MTT assay. Particle suspensions at the required concentrations were incubated with h-TERT BJ1 cells in a 96 well plate for 1 hour at $37^{\circ} \mathrm{C}$. The particle suspension was then removed and $5 \mu \mathrm{L}$ of MTT dye $\left(5 \mathrm{mg} \mathrm{mL}^{-1}\right.$ in phosphate buffer $\mathrm{pH}$ 7.4, Sigma-Aldrich) was added to each well. After 1.5 hours of incubation at $37^{\circ} \mathrm{C}$, the medium was removed and any formazan crystals produced were dissolved in $100 \mu \mathrm{L}$ of DMSO. The absorbance of each well was read on a microplate reader (Dynatech MR7000 instruments) at $550 \mathrm{~nm}$, calibrated to zero absorbance using culture medium without cells. Details of the cell culture protocol and additional electron microscopy imaging of cells with the NPs can be found in the ESI. $\dagger$

\section{Specific absorption rate (SAR) measurement}

The sample for the SAR measurement was prepared starting from an aqueous dispersion of the PEG functionalized $\mathrm{Gd}: \mathrm{Fe}_{3} \mathrm{O}_{4}$ NPs. ${ }^{22}$ A small amount of the aqueous dispersion was placed inside a polycarbonate capsule. Evaporation of the water was accelerated by gentle heating until a viscous (due to the PEG content) dry sample was obtained and no changes to the specimen weight (sample + capsule) were detected $( \pm 0.01 \mathrm{mg})$ over one day. The total specimen weight was $31 \mathrm{mg}$ with a sample mass (PEG 600-DPA functionalized $\mathrm{Gd}: \mathrm{Fe}_{3} \mathrm{O}_{4}$ nanoparticles) of $0.82 \mathrm{mg}$.

The ability of the NPs to generate heat under external radio frequency (RF) excitation was determined by adiabatic magnetothermia. ${ }^{23}$ The specimen, kept under adiabatic conditions, was subjected to an alternating magnetic field with frequency $f$ $=111 \mathrm{kHz}$ and amplitude $H_{0}=3 \mathrm{kA} \mathrm{m}^{-1}$ (38 Oe) during a time interval $\Delta t$ of approximately 5 minutes. The temperature increase during the magnetic field pulse, $\Delta T$, was measured and the performance of the sample was characterized through its Specific Absorption Rate (SAR), calculated as:

$$
\mathrm{SAR}=\frac{C}{m_{\mathrm{Fe}}} \frac{\Delta T}{\Delta t}
$$

where $C\left(\mathrm{~J} \mathrm{~K}^{-1}\right)$ is the heat capacity of the specimen and $m_{\mathrm{Fe}}$ is the mass of Fe present in the sample, calculated from the EELS elemental analysis. The reported SAR value is an average of four independent room temperature measurements.

\section{Results and discussion}

\section{Gd: $\mathrm{Fe}_{3} \mathrm{O}_{4} \mathrm{NP}$ synthesis and characterisation}

TEM images of a typical sample of NPs are presented in Fig. 1. The particles are well-defined and octahedral, with a measured average long axis length of $12.6 \pm 2.6 \mathrm{~nm}$ (Fig. 1a). The size and shape of nanoparticles is determined in part by the adsorption of molecular species during synthesis, particularly if binding affinities vary with the crystallographic orientation of exposed surfaces. ${ }^{4}$ Octahedral or truncated octahedral $\mathrm{Fe}_{3} \mathrm{O}_{4}$ nanoparticles are known to arise from the competitive adsorption of oleate and oleylamine species, ${ }^{24}$ the relative concentrations of which determine the precise NP shape. ${ }^{25}$ The NP shape can also be perturbed by the presence of other molecules, which includes the decomposition products of the molecular precursor used here. ${ }^{5}$ High resolution TEM (Fig. 1b) confirmed 

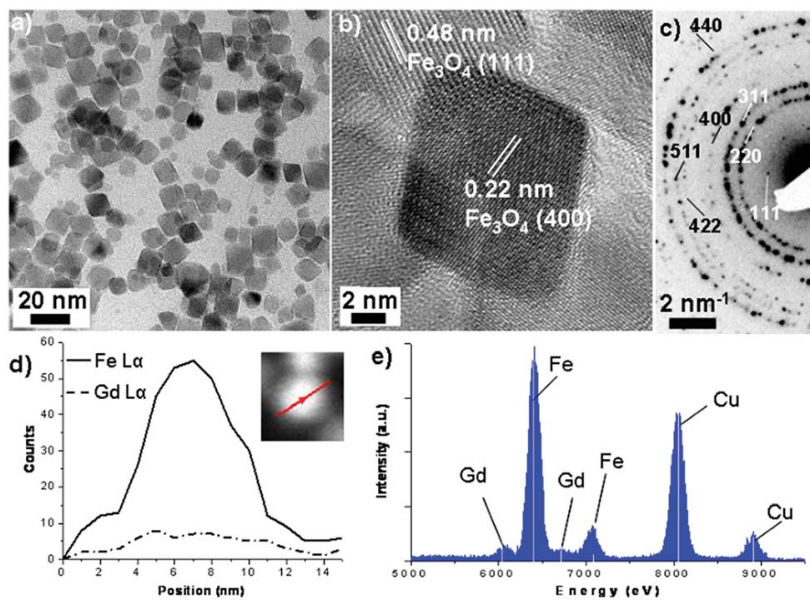

Fig. 1 TEM analysis of the $\mathrm{Gd}: \mathrm{Fe}_{3} \mathrm{O}_{4}$ particles, showing (a) an overview of the NPs, with a clear prevalence of octahedral particles. (b) High resolution TEM image of a typical octahedral particle, annotated with fringe spacings that are consistent with those of magnetite. (c) SAED, with diffraction rings indexed with those of the magnetite $\left(\mathrm{Fe}_{3} \mathrm{O}_{4}\right)$ structure. (d) Iron and gadolinium $L_{\alpha}$ signal intensities from a STEM EDX line trace across a single particle (see inset dark-field image), showing the co-location of Fe and Gd in a single NP. (e) EDX spectrum obtained from a group of particles, showing the presence of iron and gadolinium. The $\mathrm{Cu}$ peaks arise from secondary scattering from the TEM support grid.

that the particles are single crystalline, with lattice fringes clearly visible and with the fringe spacings consistent with those of magnetite. The inverse spinel crystal structure typical of $\mathrm{Fe}_{3} \mathrm{O}_{4}$ was confirmed via selected area electron diffraction (SAED, Fig. 1c), suggesting that $\mathrm{Gd}^{3+}$ uptake does not have a significant effect on overall crystal structure. A STEM EDX line trace across a single particle and a composite EDX spectrum obtained from a group of particles are shown in Fig. 1d and e and clearly support the presence of both iron and gadolinium in the particles. There is no clear variation in the $\mathrm{Gd}: \mathrm{Fe}$ ratio across the particle, nor contrast variation in STEM images that would suggest Gd segregation or a core-shell morphology and we conclude that the Gd is uniformly distributed throughout the magnetite lattice.

STEM-EELS measurements were also performed and have the advantage that the obtained spectra provide an accurate representation of the chemical composition of a material at a given point without, for example, the secondary effects that produce the spurious $\mathrm{Cu}$ signal in EDX. This spatially-resolved compositional analysis is critical in ruling out the presence of inhomogeneous products and to definitively demonstrate Gd incorporation within the particles. To minimise electron beam damage, data was acquired by 'hopping' the electron beam from particle to particle, dwelling on each particle for 5 seconds. The particles chosen for this measurement are shown in Fig. 2a. The EELS spectra obtained from roughly 35 particles is presented in Fig. $2 \mathrm{~b}-\mathrm{d}$, which shows well defined edges for oxygen-K and iron- $\mathrm{L}_{2,3}$ edges, in addition to a signal from the gadolinium- $\mathrm{M}_{5,4}$ edges. The calculated elemental composition was determined to be Fe: $47.6 \%$, O: $50.8 \%$ and $\mathrm{Gd}: 1.6 \%$, using standard a)
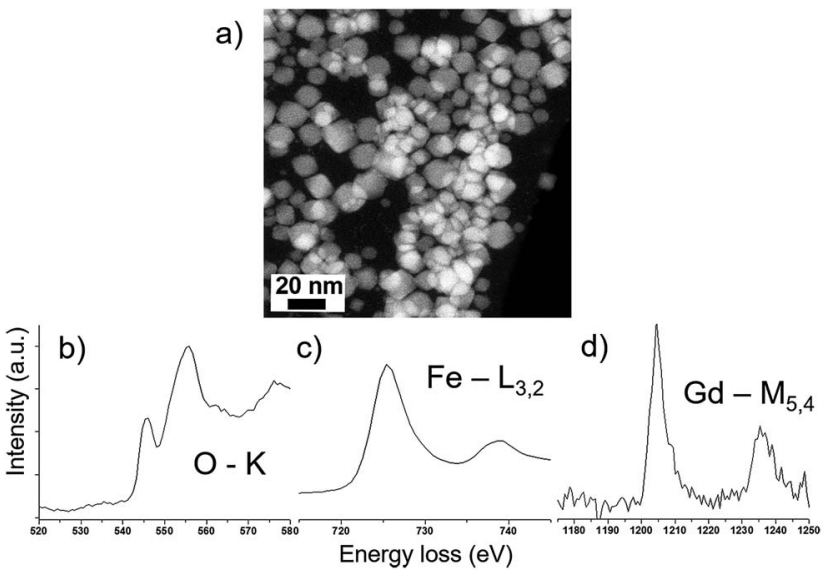

Fig. 2 (a) Dark-field STEM image of typical $\mathrm{Gd}: \mathrm{Fe}_{3} \mathrm{O}_{4}$ NPs used for EELS analysis (in dark field images, heavy material such as the nanoparticles appear bright). (b-d) Background-subtracted EELS edges, showing the presence of $\mathrm{O}, \mathrm{Fe}$ and $\mathrm{Gd}$ in the particles.

background-fitting, removal of plural scattering and EELS crosssections within the Gatan Digital Micrograph software. ${ }^{26}$ Subsequent EELS measurements taken from a larger number of samples across the grid indicate a variation in fitted Gd content from $1.6 \%$ to $2.5 \%$, giving a mean Gd content for the MNP sample of around $2( \pm 0.4) \mathrm{mol} \%$.

When compared with other methods for producing $\mathrm{Gd}: \mathrm{Fe}_{3} \mathrm{O}_{4}$ particles, our single source high-temperature method has distinct advantages. For example, a previous mild coprecipitation method between iron and gadolinium chlorides at $65{ }^{\circ} \mathrm{C}$ produced ill-defined particles with a single-domain maximum gadolinium level of $\sim 1 \mathrm{~mol} \% .^{27}$ The authors were able to increase the $\mathrm{Gd}^{3+}$ levels to a maximum of $1.4 \mathrm{~mol} \%$, though the resultant particles were polydisperse, aggregated and believed to be multidomain. It should be noted that the coprecipitation method does allow for some control over the level of $\mathrm{Gd}^{3+}$ dopant, ${ }^{28}$ though this is often at the expense of control over size distribution or particle morphology, which is retained in our thermal decomposition method. In contrast, our single source method produced well defined NPs with a gadolinium content in the range $2( \pm 0.4) \mathrm{mol} \%$. The observed gadolinium levels for our single source particles are in agreement with levels seen elsewhere in the literature. Wang et al. reported a maximum $\mathrm{Gd}^{3+}$ dopant level of $2.85 \mathrm{~mol} \%$ in cobalt-ferrite microparticles. ${ }^{29}$ Above this level, the nucleation of a separate $\mathrm{GdFeO}_{3}$ perovskite phase was observed, suggesting an upper limit to Gd incorporation within the magnetite lattice of a few $\mathrm{mol} \%$. This is not surprising given the difference in ionic radii between $\mathrm{Gd}^{3+}(107.8 \mathrm{pm}), \mathrm{Fe}^{2+}(78 \mathrm{pm})$ and $\mathrm{Fe}^{3+}(65 \mathrm{pm}) .^{30}$

The SAED measurements of Fig. 1c confirm that the magnetite structure has been retained upon gadolinium doping. We found no evidence for the formation of other gadolinium ferrite phases, such as perovskite $\mathrm{GdFeO}_{3}$ or garnet $\mathrm{Gd}_{3} \mathrm{Fe}_{5} \mathrm{O}_{12} \cdot{ }^{31}$ The observed lattice parameter of $8.21 \AA$ is consistent with that of magnetite and may reflect the fact that there are two competing trends in determining the lattice parameter: a reduction in lattice parameter due to relaxation effects within small NPs and lattice 
expansion due to gadolinium incorporation. ${ }^{29}$ It is possible that the incorporation of Gd may inhibit the growth of larger particles, due to increasing difficulties in accommodating lattice strain. Despite thorough experimentation, we were unable to obtain larger particles by altering the reaction conditions implying that the $12.6 \mathrm{~nm}$ particles obtained here may represent the upper grain size limit using these reaction conditions. However, we note that previous work on the $\mathrm{Gd}: \mathrm{Fe}_{3} \mathrm{O}_{4}$ system yielded particles up to $33 \mathrm{~nm}$ with increasing $\mathrm{Gd}^{3+}$ content, albeit with an increase in polydispersity and above $\sim 25 \mathrm{~nm}$ the particles became multi-domain. ${ }^{27}$

Magnetic measurements were performed to investigate the effect of magnetic ion doping on the magnetisation of the doped magnetite particles. Hysteresis loops recorded at $100 \mathrm{~K}$ and $300 \mathrm{~K}$ are provided in Fig. 3a. Field-cooled (FC) and zero field-cooled (ZFC) measurements were also performed and are shown in Fig. 3b. The hysteresis loops clearly show the superparamagnetic behaviour of the particles. Interestingly, the magnetisation $(M)$ values for the $\mathrm{Gd}: \mathrm{Fe}_{3} \mathrm{O}_{4}$ particles (32.9 and $28.9 \mathrm{emu} \mathrm{g}^{-1}$ at 100 and $300 \mathrm{~K}$ respectively) were lower than the $96.4 \mathrm{emu} \mathrm{g}^{-1} \mathrm{ex}^{-}$ pected for bulk magnetite at room temperature. ${ }^{32}$ This follows similar trends for lanthanide doped magnetite, as Drake et al. reported room temperature $M$ values of $65.7 \mathrm{emu} \mathrm{g}^{-1}$ for superparamagnetic $\mathrm{Gd}_{0.02} \mathrm{Fe}_{2.98} \mathrm{O}_{4}$ NPs, synthesised by the coprecipitation method. ${ }^{1}$ Liang et al. also prepared lanthanidedoped magnetite particles using the co-precipitation method. Of these the gadolinium-doped particles showed the highest room temperature $M$ values of $45.9 \mathrm{emu}^{-1}{ }^{-33}$ De Silva et al. published a high temperature thermolysis route to $\mathrm{Ln}: \mathrm{Fe}_{3} \mathrm{O}_{4}(\mathrm{Ln}$ $=\mathrm{Sm}, \mathrm{Eu}$, and $\mathrm{Gd}$ ) particles. ${ }^{34}$ In this report the $M$ values for $\mathrm{Sm}: \mathrm{Fe}_{3} \mathrm{O}_{4}$ and $\mathrm{Eu}: \mathrm{Fe}_{3} \mathrm{O}_{4}$ particles are 42.1/31.3 and 29.8/23.6 emu $\mathrm{g}^{-1}$ (Sm and Eu particles at $60 \mathrm{~K}$ and $300 \mathrm{~K}$, respectively), though no comment is made regarding the $M$ values of the $\mathrm{Gd}: \mathrm{Fe}_{3} \mathrm{O}_{4}$ particles. This decrease seems to be not limited to the low $\mathrm{Gd}^{3+}$ doping level since it has been also determined for $\mathrm{Gd}_{x} \mathrm{Fe}_{3-x} \mathrm{O}_{4}$ NPs (average size $8 \mathrm{~nm}$ ) obtained by standard chemical precipitation process for the compositional range $0.1<x<1.9 .^{35}$ Decreasing $M$ values with increasing levels of $\mathrm{Ln}^{3+}$ doping have also been observed for other ferrite systems, such as gadolinium doped in $\gamma-\mathrm{Fe}_{2} \mathrm{O}_{3}$ powders, ${ }^{36}$ cobalt-ferrite microparticles, ${ }^{29}$ and $\mathrm{Cu}_{0.5} \mathrm{Zn}_{0.5} \mathrm{Fe}_{2-x} \mathrm{Ln}_{x} \mathrm{O}_{4}$ powders, where a decrease in magnetisation upon $\mathrm{Ln}^{3+}$ doping (increasing $x$ from 0 to 0.02) was observed. ${ }^{34}$
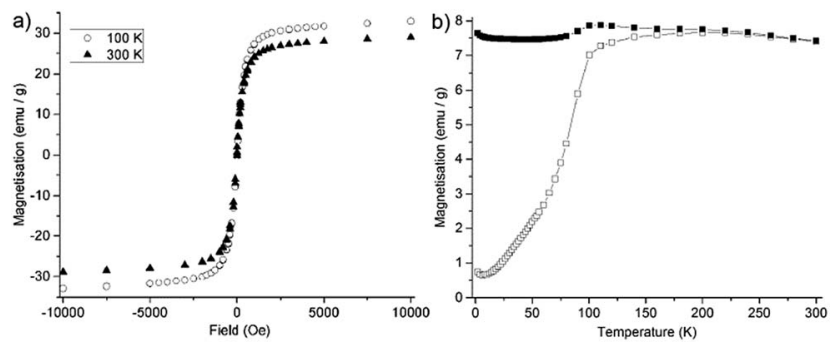

Fig. 3 (a) Hysteresis loops for $\mathrm{Gd}: \mathrm{Fe}_{3} \mathrm{O}_{4}$ nanoparticles recorded at 100 and $300 \mathrm{~K}$. (b) Zero field cooled (open symbols) and field-cooled (closed symbols) magnetisation of octahedral $12 \mathrm{~nm} \mathrm{Gd:Fe} \mathrm{O}_{4}$ particles in an applied field of 100 Oe.
The most likely explanation for the observed decrease in magnetisation upon doping is that $\mathrm{Ln}^{3+}$ ions cause a disruption to ferrimagnetic ordering. ${ }^{1}$ The difference in ionic radii between gadolinium(III) and iron(II)/(III) ions is in the order of $30 \mathrm{pm}$ (for $\mathrm{Fe}^{2+}$ ) and $43 \mathrm{pm}\left(\right.$ for $\mathrm{Fe}^{3+}$ ). In lanthanide-doped magnetite, the large $\mathrm{Gd}^{3+}$ ion will go into the octahedral B sites of the lattice, increasing strain in the lattice and therefore reducing the overall crystalline symmetry, which will increase the magnetocrystalline anisotropy. ${ }^{29,37}$ Reduction of the overall crystalline symmetry may also disrupt the ferrimagnetic ordering within the magnetite lattice, which would contribute to the lower overall magnetisation of the particle. The decrease in magnetisation seen in our $\mathrm{Gd}: \mathrm{Fe}_{3} \mathrm{O}_{4} \mathrm{NPs}$ may therefore appear to be the consequence of two factors: a decrease in long range magnetic ordering upon insertion of large $\mathrm{Gd}^{3+}$ ions into the $\mathrm{Fe}_{3} \mathrm{O}_{4}$ matrix and an increase in magnetic anisotropy. This is an encouraging result, as Gd doping provides a way of modifying the anisotropy of the particles.

Field cooled (FC) and zero field cooled measurements (ZFC) were recorded for the $\mathrm{Gd}: \mathrm{Fe}_{3} \mathrm{O}_{4} \mathrm{NPs}$, and the data are presented in Fig. $3 \mathrm{~b}$, from which a blocking temperature $\left(T_{\mathrm{B}}\right)$ of $\sim 200 \mathrm{~K}$ was extracted. The measured $T_{\mathrm{B}}$ is in agreement with previously reports; for example, Park et al. reported $T_{\mathrm{B}}$ values of $\sim 110 \mathrm{~K}$ and $\sim 225 \mathrm{~K}$ for 12 and $16 \mathrm{~nm}$ particles respectively. ${ }^{6}$ The $T_{\mathrm{B}}$ is directly related to the magnetic anisotropy and the volume of the particles. However, it is strongly affected by the effect of magnetic interactions ${ }^{38}$ and therefore the $T_{\mathrm{B}}$ values do not contradict the aforementioned increase in magnetic anisotropy.

Turning to MH measurements, the hydrophobic oleylamine/ oleic acid surfactant layer protecting the as-prepared particles was first exchanged with a hydrophilic PEG derivative in order to facilitate aqueous dispersion of the particles. Successful surfactant exchange was confirmed by an increase in the hydrodynamic radius and by the evident stability of the PEG coated particles in aqueous dispersion (see Fig. S3†). The PEG coated particles were then tested for cell uptake and toxicity using human fibroblast cells. The MTT assay showed that cell metabolic activity (viability) remained in the $70-80 \%$ region for $\mathrm{Gd}: \mathrm{Fe}_{3} \mathrm{O}_{4}$ particles for concentrations below $0.1 \mathrm{mg} \mathrm{mL}^{-1}$ and in the $90-100 \%$ region for undoped $\mathrm{Fe}_{3} \mathrm{O}_{4}$ particles (see Fig. $\mathrm{S} 4 \dagger$ ). The reasons behind the slight decrease in cell viability in the gadolinium doped samples are unclear; it may be possible that there is 'leakage' of free $\mathrm{Gd}^{3+}$ from the doped particles which is in turn having a detrimental effect on cell viability. This would have to be improved before potential clinical applications of $\mathrm{Gd}: \mathrm{Fe}_{3} \mathrm{O}_{4}$ nanoparticles could be realised, ${ }^{39}$ with further studies to improve the surface coating needed. Optical fluorescence microscopy and electron microscopy were performed on the cells incubated with both doped and undoped particles (see Fig. S5 and S6† respectively). Fluorescence microscopy shows a change in phenotype, with a more rounded cell shape, and cytoskeletal reorganisation on incubation with the particles, most likely due to cellular uptake (Fig. S5†), whilst electron microscopy clearly demonstrated an increase in cell membrane activity and particle uptake into cells (using SEM and TEM, respectively, Fig. $\left.\mathbf{S 6} \dagger^{\dagger}\right)^{40}$

The specific absorption rate (SAR) of the PEG-coated NPs was determined at room temperature by adiabatic magnetothermia. ${ }^{23}$ 
As the specimen heat capacity, $C$, is derived only from the polycarbonate capsule (the estimated sample contribution is lower than $5 \%$ and can be considered as negligible), the calculated SAR value is $3.7 \pm 0.6 \mathrm{~W} \mathrm{~g}_{\mathrm{Fe}}{ }^{-1}$.

There is little literature about SAR measurements of $\mathrm{Gd}^{3+}$ doped iron oxide NPs for comparison. An intriguing SAR enhancement with $\mathrm{Gd}^{3+}$ doping respect to pure magnetite has been reported for $\mathrm{Gd}_{x} \mathrm{Fe}_{3-x} \mathrm{O}_{4}$ with $x=0.01-0.03$ which increases as the Gd doping increases. ${ }^{1,27}$ However, size effects cannot be ruled out since the particle diameter also increases, from 13 to $19 \mathrm{~nm}$, with the $\mathrm{Gd}^{3+}$ doping level. SAR also depends strongly on the alternating magnetic field parameters. While our measurements were performed under low field amplitude $H_{0}=3$ $\mathrm{kA} \mathrm{m}^{-1}$ and $f=111 \mathrm{kHz}$, the SAR values around $30-40 \mathrm{~W} \mathrm{~g}_{\mathrm{Fe}}{ }^{-1}$ reported in ref. 1 and 23 were measured under $H_{0}=246$ Oe $\left(=19.5 \mathrm{kA} \mathrm{m}^{-1}\right)$ and $f=52 \mathrm{kHz}$. The dependence of SAR on the alternating field parameters depends on the size, polydispersity, anisotropy constant and the strength of the magnetic interactions, and cannot be predicted a priori.$^{\mathbf{4 1 , 4 2}}$ However, as a rule of thumb, a square (linear) dependence with $H_{0}(f)$ can be considered, assuming the linear response theory and a non-interacting nanoparticle assembly. ${ }^{43}$ The extrapolation of the experimental values in the literature ${ }^{1,27}$ to our experimental alternating magnetic field parameters gives a SAR of $1.5-2 \mathrm{~W} \mathrm{~g}_{\mathrm{Fe}}{ }^{-1}$. Hence, the sample studied in the present work, with a higher $\mathrm{Gd}^{3+}$ content, obtained using a single-source precursor shows an improved SAR value with respect to previously reported values. We postulate that the effect of the $\mathrm{Gd}^{3+}$ dopant on the magnetic anisotropy constant is the reason for such enhancement.

\section{Conclusion}

A bimetallic iron gadolinium single-source precursor was used to synthesise high quality gadolinium-doped magnetite ( $\left.\mathrm{Gd}: \mathrm{Fe}_{3} \mathrm{O}_{4}\right)$ NPs by a surfactant-assisted thermolysis route. We have shown that polynuclear complexes can be used as precursors in the synthesis of MNPs and that mixed metal complexes provide a facile route to obtain doped particles, which can be otherwise difficult to prepare. TEM measurements showed that $\sim 12 \mathrm{~nm}$ diameter octahedral particles were formed, with EDX and EELS measurements confirming the presence of gadolinium in the particles in the region of $2 \pm 0.4 \mathrm{~mol} \%$. SQUID measurements revealed that the presence of gadolinium ions in the particles is responsible for a decrease in the magnetisation. This could be accounted for by a change in the magneto-crystalline structure of the magnetite lattice due to the doping of the large $\mathrm{Gd}^{3+}$ ions, which will induce a change in the magneto-crystalline anisotropy. Biological studies show that cells exposed to $\mathrm{Gd}: \mathrm{Fe}_{3} \mathrm{O}_{4} \mathrm{NPs}$ do not react adversely and $\mathrm{MH}$ measurements showed the particles to have a relatively high SAR value of $3.7 \pm 0.6 \mathrm{~W} \mathrm{~g}_{\mathrm{Fe}}{ }^{-1}$ (when $H_{0}=3 \mathrm{kA} \mathrm{m}^{-1}$ and $f=111 \mathrm{kHz}$ ).

\section{Acknowledgements}

We thank Dr Emma Humphreys-Williams at the Imaging and Analysis Centre (IAC), Natural History Museum, London for MNP metal content analysis. FJD gratefully acknowledges a scholarship from the University of Glasgow and DAM a fellowship from the UK Engineering and Physical Sciences Research Council (grant ref. EP/I00419X/1). IA was supported by a JAE-Predoc 2010 (CSIC program "Junta para la ampliación de estudios"), co-funded by the European Social Fund. We also acknowledge financial support by the Spanish MEC (MAT2011-24284) and MINECO (Project MAT2013-44063-R).

\section{References}

1 P. Drake, H.-J. Cho, P.-S. Shih, C.-H. Kao, K.-F. Lee, C.-H. Kuo, X.-Z. Lin and Y.-J. Lin, J. Mater. Chem., 2007, 17, 4914-4918.

2 K. Krishnan, IEEE Trans. Magn., 2010, 46, 2523-2558.

3 A. Hervault and N. T.-K. Thanh, Nanoscale, 2014, 6, 1155311573.

4 F. J. Douglas, D. A. MacLaren and M. Murrie, $R S C A d v ., 2012$, 2, 8027-8035.

5 F. J. Douglas, D. A. MacLaren, F. Tuna, W. M. Holmes, C. C. Berry and M. Murrie, Nanoscale, 2014, 6, 172-176.

6 J. Park, K. An, Y. Hwang, J. Park, H. Noh, J. Kim, J. Park, N. Hwang and T. Hyeon, Nat. Mater., 2004, 3, 891-895.

7 W. S. Seo, H. H. Jo, K. Lee, B. Kim, S. J. Oh and J. T. Park, Angew. Chem., Int. Ed., 2004, 43, 1521-3773.

8 A. L. Cortajarena, D. Ortega, S. M. Ocampo, A. GonzálezGarcía, P. Couleaud, R. Miranda, C. Belda-Iniesta and A. Ayuso-Sacido, Nanobiomedicine, 2014, 1, 1-20.

9 L. Li, W. Jiang, K. Luo, H. Song, F. Lang, Y. Wu and Z. Gu, Theranostics, 2013, 3, 595-615.

10 K. Maier-Hauff, R. Rothe, R. Scholz, U. Gneveckow, B. Thiesen, A. Feussner, A. Deimling, N. Waldoefner, R. Felix and A. Jordan, J. Neuro-Oncol., 2007, 81, 53-60.

11 K. Maier-Hauff, F. Ulrich, D. Nestler, H. Niehoff, P. Wust, B. Thiesen, H. Orawa, V. Budach and A. Jordan, J. NeuroOncol., 2011, 103, 317-324.

12 J.-T. Jang, H. Nah, J.-H. Lee, S. H. Moon, M. G. Kim and J. Cheon, Angew. Chem., Int. Ed., 2009, 48, 1234-1238.

13 K. H. Bae, Y. B. Kim, Y. Lee, J. Hwang, H. Park and T. Gwan Park, Bioconjugate Chem., 2010, 21, 505-512.

14 Z. Zhou, L. Wang, X. Chi, J. Bao, L. Yang, W. Zhao, Z. Chen, X. Wang, X. Chen and J. Gao, ACS Nano, 2013, 7, 3287-3296.

15 T.-H. Shin, Y. Choi, S. Kim and J. Cheon, Chem. Soc. Rev., 2015, 44, 4501-4516.

16 N. Xiao, W. Gu, H. Wang, Y. Deng, X. Shi and L. Ye, J. Colloid Interface Sci., 2014, 417, 159-165.

17 X. Wang, Z. Zhou, Z. Wang, Y. Xue, Y. Zeng, J. Gao, L. Zhu, X. Zhang, G. Liu and X. Chen, Nanoscale, 2013, 5, 8098-8104. 18 E. Roy, S. Patra, R. Madhuri and P. K. Sharma, Colloids Surf., $B, 2016,142,248-258$.

19 S. Chen, D. A. MacLaren, R. T. Baker, J. N. Chapman, S. Lee, D. J. Cole-Hamilton and P. André, J. Mater. Chem., 2011, 21, 3646-3654.

20 F. J. Douglas, PhD Thesis, University of Glasgow, 2012.

21 A. Ferguson, J. McGregor, E. K. Brechin, L. H. Thomas and M. Murrie, Dalton Trans., 2009, 9395-9397.

22 J. Xie, C. Xu, N. Kohler, Y. Hou and S. Sun, Adv. Mater., 2007, 19, 3163-3166. 
23 E. Natividad, M. Castro and A. Mediano, Appl. Phys. Lett., 2008, 92, 093116.

24 L. Zhang, J. Wu, H. Liao, Y. Hou and S. Gao, Chem. Commun., 2009, 4378-4380.

25 Q. Song, Y. Ding, Z. L. Wang and Z. J. Zhang, J. Phys. Chem. B, 2006, 110, 25547-25550.

26 Gatan Inc. website, http://www.gatan.com/, accessed Feburary 2016.

27 P.-S. Jiang, P. Drake, H.-J. Cho, C.-H. Kao, K.-F. Lee, C.-H. Kuo, X.-Z. Lin and Y.-J. Lin, J. Nanosci. Nanotechnol., 2012, 12, 5076-5081.

28 G. Zhang, R. Du, L. Zhang, D. Cai, X. Sun, Y. Zhou, J. Zhou, J. Qian, K. Zhong, K. Zheng, D. Kaigler, W. Liu, X. Zhang, D. Zou and Z. Wu, Adv. Funct. Mater., 2015, 25, 6101-6111.

29 Q. Wang, S. Li, A. Wu and H. Yang, J. Magn. Magn. Mater., 2009, 321, 2622-2626.

30 C. E. Housecroft and A. G. Sharpe, Inorganic Chemistry, Pearson Education, 2001.

31 F. Söderlind, L. Selegârd, P. Nordblad, K. Uvdal and P.-O. Käll, J. Sol-Gel Sci. Technol., 2009, 49, 253-259.

32 A. Angermann and J. Topfer, J. Mater. Sci., 2008, 43, 51235130 .
33 X. Liang, X. Wang, J. Zhuang, Y. Chen, D. Wang and Y. Li, Adv. Funct. Mater., 2006, 16, 1805-1813.

34 C. R. D. Silva, S. Smith, I. Shim, J. Pyun, T. Gutu, J. Jiao and Z. Zheng, J. Am. Chem. Soc., 2009, 131, 6336-6337.

35 V. N. Nikoforov and B. L. Oksengendler, Inorg. Mater., 2014, 50, 1222-1225.

36 A. Nikumbh, J. Mater. Sci., 1990, 25, 3773-3779.

37 Y.-I. Kim, W. B. Im, M. K. Jeon, Y.-H. Lee, K.-B. Kim and K.-S. Ryu, J. Nanosci. Nanotechnol., 2011, 11, 810-814.

38 I. Andreu, L. Solozabal, E. Natividad and O. Roubeau, ACS Nano, 2015, 9, 1408-1419.

39 J. G. Penfield and R. F. Reilly, Nat. Rev. Nephrol., 2007, 3, 654668.

40 C. C. Berry, J. Mater. Chem., 2005, 15, 543-547.

41 J. Carrey, B. Mehdaoui and M. Respaud, J. Appl. Phys., 2011, 109, 083921.

42 D. Serantes, D. Baldomir, C. Martinez-Boubeta, K. Simeonidis, M. Angelakeris, E. Natividad, M. Castro, A. Mediano, D.-X. Chen, A. Sanchez, L. I. Balcells and B. Martínez, J. Appl. Phys., 2010, 108, 073918.

43 R. E. Rosensweig, J. Magn. Magn. Mater., 2002, 252, 370-374. 